\title{
CARACTERIZAÇÃO ÓPTICA DE CORANTES NATURAIS EXTRAÍDOS DE PLANTAS ORNAMENTAIS
}

\author{
M. THOMAZ ${ }^{1,2}$, D. G. FELISBINO ${ }^{1}$, D. N. $\operatorname{MESSIAS}^{1}$, A. A. ANDRADE ${ }^{1}$, V. PILLA $^{1}$ \\ ${ }^{1}$ Universidade Federal de Uberlândia, Instituto de Física \\ ${ }^{2}$ Universidade Federal de Uberlândia, Faculdade de Engenharia Química \\ E-mail para contato: maarinathomaz@gmail.com
}

\begin{abstract}
RESUMO - O presente trabalho tem como base a extração da antocianina, corante natural, extraído de plantas ornamentais. Foram realizados diversos testes para definir o melhor tempo de centrifugação das amostras de antocianina, para a otimização do processo de extração do corante da planta Tradescantia pallida $\mathrm{cv}$ purpúrea. Os melhores resultados foram avaliados através das caracterizações ópticas, como absorbância e fluorescência, maximizando suas intensidades com a modificação do processo de extração do corante. Em adição, outras técnicas foram utilizadas para a determinação de propriedades, tais como pH e índice de refração.
\end{abstract}

\section{INTRODUÇÃO}

A antocianina é um pigmento natural encontrado em plantas, como a utilizada neste trabalho, a Tradescantia pallida cv purpúrea, de acordo com Mendes et al. (2016). As antocianinas são uma parte do grupo geral de compostos de flavonoides que são caracterizados pelo núcleo flavílio. Sua molécula consiste em uma base de núcleo aglicona, um grupo de açúcares e um grupo de acilo de ácidos. As antocianinas são estruturalmente caracterizadas pela presença do esqueleto contendo 15 átomos de carbono na forma $\mathrm{C}_{6}-\mathrm{C}_{3}-\mathrm{C}_{6}$. Porém, segundo Brouillard et al. (1982) e Francis e Markakis (1989), ao contrário dos outros flavonóides, as antocianinas absorvem fortemente na região visível do espectro, conferindo uma infinidade de cores, dependendo do meio de ocorrência. A descoberta da estrutura e síntese de antocianina ocorreram durante os primeiros anos do século 20, de acordo, Pina et al. (2012), e com o passar dos anos foram realizadas novas descobertas sobre o pigmento, como a importância de sua coloração e propriedades químicas.

Existe um grande interesse no estudo das antocianinas em diversas áreas, como na saúde, devido ao seu grande potencial terapêutico, na indústria, com destaque para as aplicações na fabricação de vinhos e como corantes naturais, e também na área de ensino em química, onde servem como indicadores de pH, segundo Soares e Cavalheiro (2001). Vários trabalhos demonstram que as antocianinas apresentam atividades bioquímicas e farmacológicas com vários efeitos biológicos, incluindo ações antioxidantes, antimicrobianos, antivirais e anticarcinogênicos, de acordo com Mendes et al. (2016).

Neste trabalho, o objetivo inicial foi em otimizar o processo da extração da antocianina em solução aquosa. As caracterizações das soluções aquosas de antocianinas em diferentes concentrações foram realizadas utilizando as técnicas de absorção, fluorescência, 
índice de refração e potencial de hidrogênio $(\mathrm{pH})$. Posteriormente, pretende-se utilizar esses materiais em aplicações bioambientais.

\section{PROCEDIMENTO EXPERIMENTAL}

O procedimento consiste em coleta das folhas de Tradescantia pallida cv purpúrea (Figura 1) e assepsia das mesmas. Depois, as folhas foram medidas tanto em comprimento quanto em largura e realizou-se as medidas das massas na balança (Shimadzu AY220). O comprimento médio das folhas utilizadas é de $(10.6 \pm 0.4) \mathrm{cm}$, e a largura média é de $(3.3 \pm$ $0.3) \mathrm{cm}$.

Figura 1 - Folhas de Tradescantia pallida cv purpúrea.

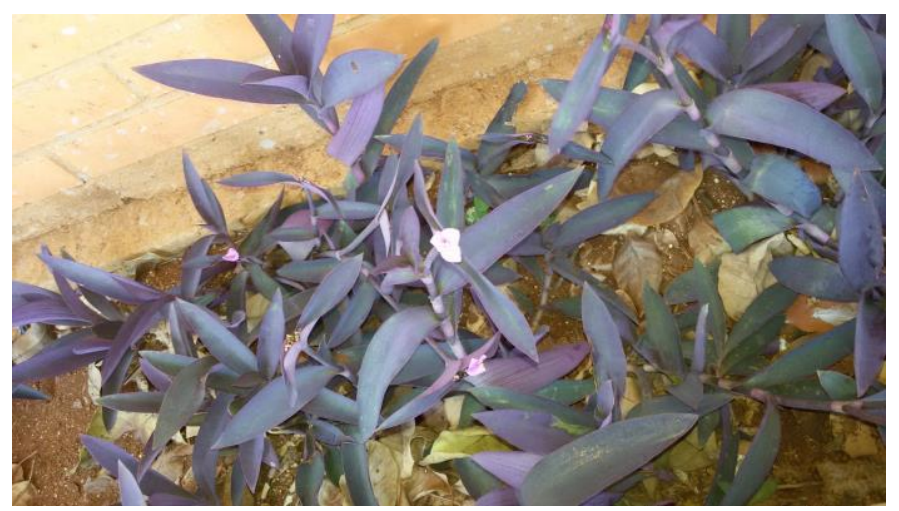

Após fazer as pesagens, preparou-se as amostras com as folhas em água destilada em diferentes concentrações (0.01-0.6) g/mL. As amostras foram maceradas (Figura 2), filtradas e centrifugadas $(7200 \mathrm{rpm})$. Foram realizados diversos testes com tempos de centrifugações 30$120 \mathrm{~min}$.

Figura 2- Maceração das amostras.

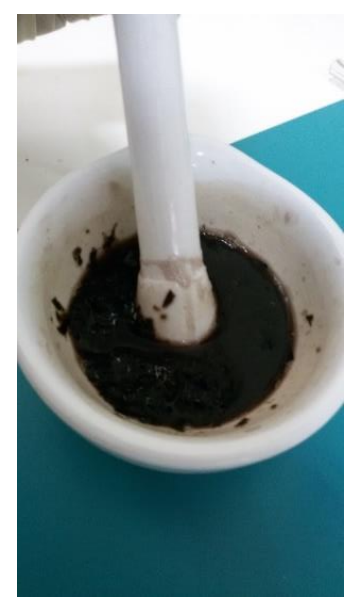


Foram realizadas medidas de absorbância, fluorescência, índice de refração e pH em todas as amostras. A absorbância foi medida usando um Ocean Optics, e na fluorescência usou-se um laser DPSSL Driver (modelo MGL532) de $22 \mathrm{~mW}$ de potência. Uma cubeta óptica de $1 \mathrm{~cm}$ de caminho óptico foi utilizada nas medidas de absorção e fluorescência. Para o índice de refração usou-se o aparelho Pocket refractometer da marca Atago e, para as medidas de pH, um aparelho da marca Hanna (modelo HI 2221).

\section{RESULTADOS E DISCUSSÕES}

Na Figura 3 são apresentados os resultados dos espectros de fluorescência e absorbância para as amostras de antocianina extraídas em solução aquosa. Essas medidas foram realizadas para amostras extraídas em diferentes tempos de centrifugações (30-120 min). Observa-se que para o tempo de 90 min a intensidade de fluorescência é máxima, e que os espectros de absorção não apresentaram modificações significativas para os valores de 60$90 \mathrm{~min}$.

Figura 3- Espectros de fluorescência e absorção em solução de antocianina. As medidas são apresentadas para diferentes tempos de centrifugações utilizadas no processo de extração do corante natural.

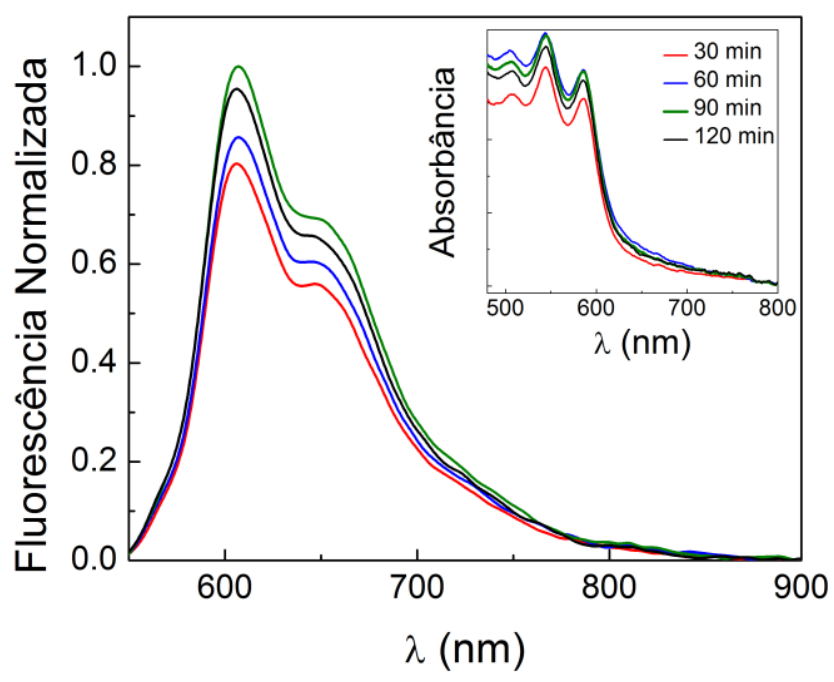

Nas Figuras 4 e 5 são apresentados os espectros de absorbância e fluorescência para as soluções aquosas de antocianina em diferentes concentrações. Em acordo com os espectros de absorção (Figura 4), percebeu-se que as amostras de antocianina apresentam bandas de absorbância na região do visível, sendo que o maior pico absorve em aproximadamente 550 nm. Nota-se também que as amostras fluorescem (Figura 5) na região entre (550 -750) nm. Esses resultados estão em acordo com os publicados na referência de Mendes et al. (2016). 
Figura 4- Espectros de absorbância para antocianina extraídas em diferentes concentrações.

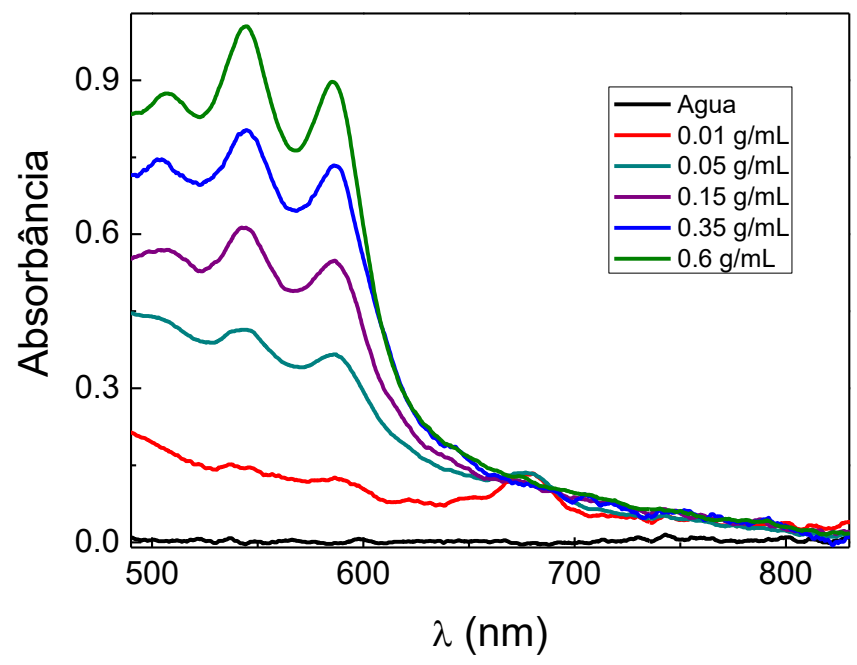

Figura 5 - Espectro de fluorescência das soluções aquosas de antocianina em diferentes concentrações.

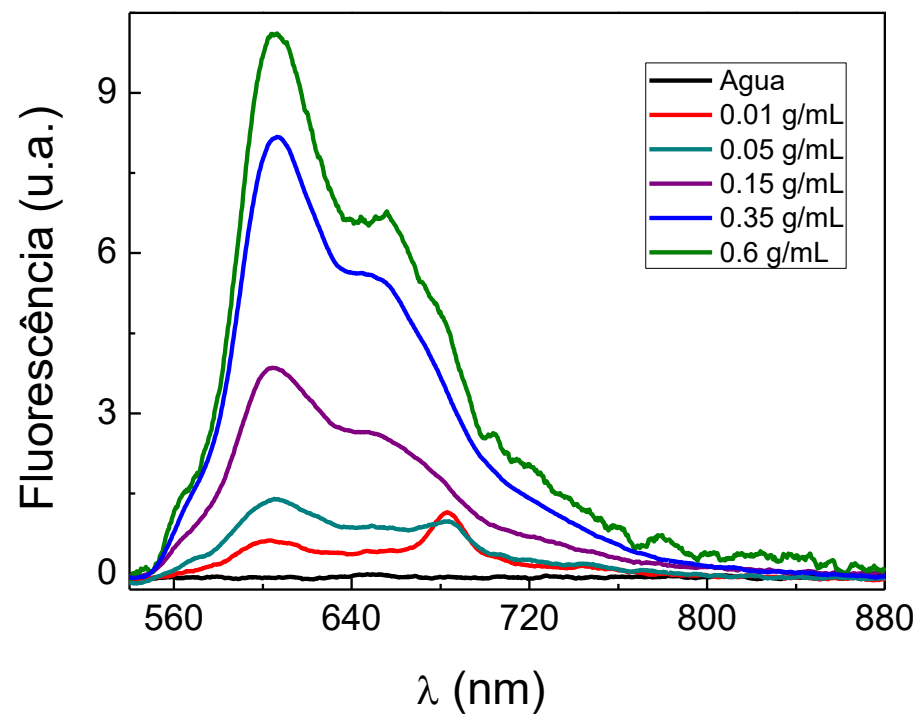

Os resultados de índice de refração (n) para diferentes concentrações de antocianina extraídas em soluções aquosas são apresentados na Figura 6. O valor médio de n obtido para as concentrações investigadas foi (1.3334 \pm 0.0004$)$, em bom acordo com o resultado para solução aquosa (Hale e Querry (1973)). Por outro lado, o valor médio do pH das amostras de antocianinas em soluções aquosas (concentrações 0.01-0.6 g/mL) obtido foi $(6.9 \pm 0.4)$. Em comparação, os valores de $\mathrm{pH}$ para as soluções de antocianinas extraídas em etanol são reportados por Mendes et al. (2016), como sendo entre 5.33-5.83 para as concentrações (0.15- 
$0.75 \mathrm{~g} / \mathrm{mL}$ ). Como próxima etapa do trabalho, serão iniciados testes para verificação da possibilidade da utilização dessas soluções de antocianinas em bioaplicações.

Figura 6 - Índice de refração em função da concentração das soluções aquosas de antocianina.

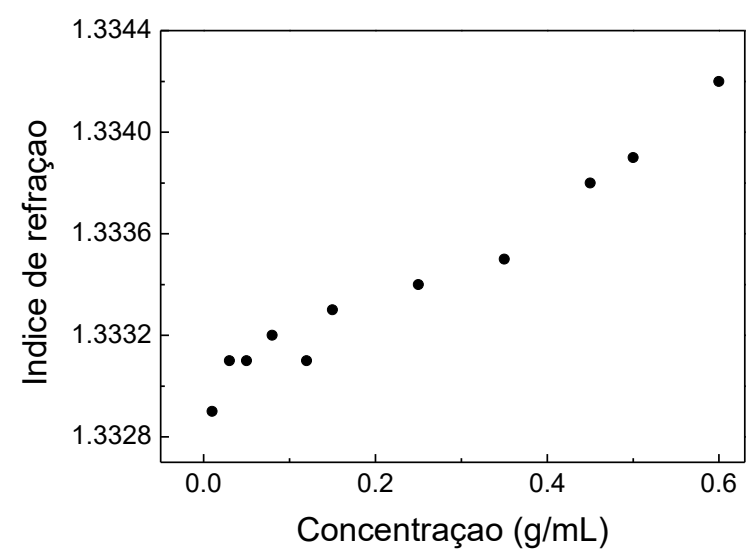

\section{CONCLUSÃO}

Após diversos testes, concluiu-se que o tempo de 90 minutos de centrifugação, para a extração da antocianina em solução aquosa, maximizou a intensidade de fluorescência. As medidas de absorbância e fluorescência são dependentes das concentrações dos corantes naturais. Os valores médios obtidos de índice de refração e pH para as concentrações de corantes avaliados neste estudo $(0.01-0.6) \mathrm{g} / \mathrm{mL}$ foram $(1.3334 \pm 0.0004)$ e $(6.9 \pm 0.4)$, respectivamente.

\section{REFERÊNCIAS}

BROUILLARD, R. Anthocyanins as food colors, MARKAKIS, P. ed., Academic Press: New York (1982), Cap. 1.

FRANCIS, F. J; MARKAKIS, P.C. Crit Rev Food Sci and Nutr 28 (1989) 273.

HALE, G.M; QUERRY, M. R. Appl Opt 12 (1973) 555.

MENDES, V; LIMA, S. R de; TORRES, J. O. B; ANTUNES, A; MESSIAS, D.N; ANDRADE, A. A; ZILIO, S. C; PILLA, V. Dyes Pigm 135 (2016) 57.

PINA, F; MELO, M. J; LAIA, C. A. T; PAROLA, A. J; LIMA, J. C. Chem Soc Rev 41 (2012) 869.

SOARES, M. H. F. B; CAVALHEIRO, E. T. G. Quim Nova 24 (2001) 408. 